\title{
Technological review of Tubular Daylight Guide System from 1982 to 2020
}

\author{
Bruno MALET-DAMOUR, Dimitri BIGOT and Harry BOYER
}

\begin{abstract}
-
T.D.G.S., "Tubular Daylight Guidance Systems", are natural lighting processes based on the transport of light. In 1990, they were judged by Littlefair as the most innovative technology in daylighting [1]. From 1982 to 2020, this paper is a state of the art on the different processes of tubular daylight guide systems. The key words used to carry out the census are: light pipe; light tube; light guide; sun pipes; solar pipes; solar light pipes; daylight pipes; tubular skylight; sun scoop; tubular daylighting device; tubular daylight guide systems; mirrored light pipe. A classification by type of process is proposed (collection, transport or diffusion) for each technology identified in the literature.
\end{abstract}

Index Terms-Light pipe, light tube, light guide, technological review

\section{INTRODUCTION}

Daylight transport devices collect and transport light over long distances within a building and are generally referred to as light pipes or light guides. They allow to increase efficiency in buildings where light is required for health, economic or architectural improvements. In 1990, the TDGS were judged by Littlefair as the most innovative technology in daylighting [1]. In the literature, many names for these systems are used. Here is a non-exhaustive listing of the names in the literature [2]:

- Light pipe;

- $\quad$ Light tube;

- Light guide;

- Sun pipes;

- Solar pipes;

- Solar light pipes;

- Daylight pipes;

- Tubular skylight;

- Sun scoop;

- Tubular daylighting device;

- Tubular Daylight Guide Systems.

TDGS are part of the daylight conveyors. They are mainly composed of three elements:

- Collector at the head of the tube: tracks the sun's path to recover as much light as possible, or simply redirects the light to the inside of the pipe;

- Tube: transports light to the area to be illuminated with a

B. Malet-Damour in associate professor in University of La Reunion, Physics and Mathematical Engineering Laboratory for Energy, Environment and Building (PIMENT), France (e-mail: bruno.malet-damour@univreunion.fr).

D. Bigot in associate professor in University of La Reunion, Physics and Mathematical Engineering Laboratory for Energy, Environment and Building (PIMENT), France (e-mail: dimitri.bigot@univ-reunion.fr). transport technique depending on the optical properties of its material (lenses, reflective pipe, prismatic pipe, solid core system). This may contain elbows that naturally influence the performance of some pipes [3][6] ;

- Diffuser (at the tube outlet): distributes the light evenly within the room to be illuminated, or throughout the tube. The latter can have an impact on the light distribution within the room to be illuminated [3], [7], [8]

Figure 1 summarizes the technological balance sheet established from 1982 to 2019.

We successively present the different collection, transport and diffusion technologies identified in the literature. We will then focus on the identification of mirrored light pipes in industry.

\section{COLLECTORS}

Light collection systems are processes that use the refractive or reflective properties of the materials, they can be passive or active. Active processes, also known as solar trackers, are expensive, but very efficient (thanks to an always optimal collection). They have the disadvantage of requiring regular maintenance. However, they may contain a concentrator. Passive devices are cheaper, but also offer lower efficiency.

For this census, we will distinguish two types of collectors to carry daylight within the pipe: active and passive systems.

\section{A. Passive collectors}

Among the passive collectors, there are collectors that do not have any moving parts. These devices have a single orientation. They are set up as soon as the light pipe is installed, depending on the best efficiency or technical possibilities. These collectors require a large collection area (and thus a correspondingly large tube size) to achieve acceptable performance, comparable to active collectors.

On the one hand the main advantage of the simplicity of the process is the price, on the other hand the disadvantage is the huge size, which can have negative effects on the building's architecture.

Four types of passive collectors exist:

- Anidolic concentrators;

H. Boyer in professor in University of La Reunion, Physics and Mathematical Engineering Laboratory for Energy, Environment and Building (PIMENT), France (e-mail: harry.boyer@univ-reunion.fr). 

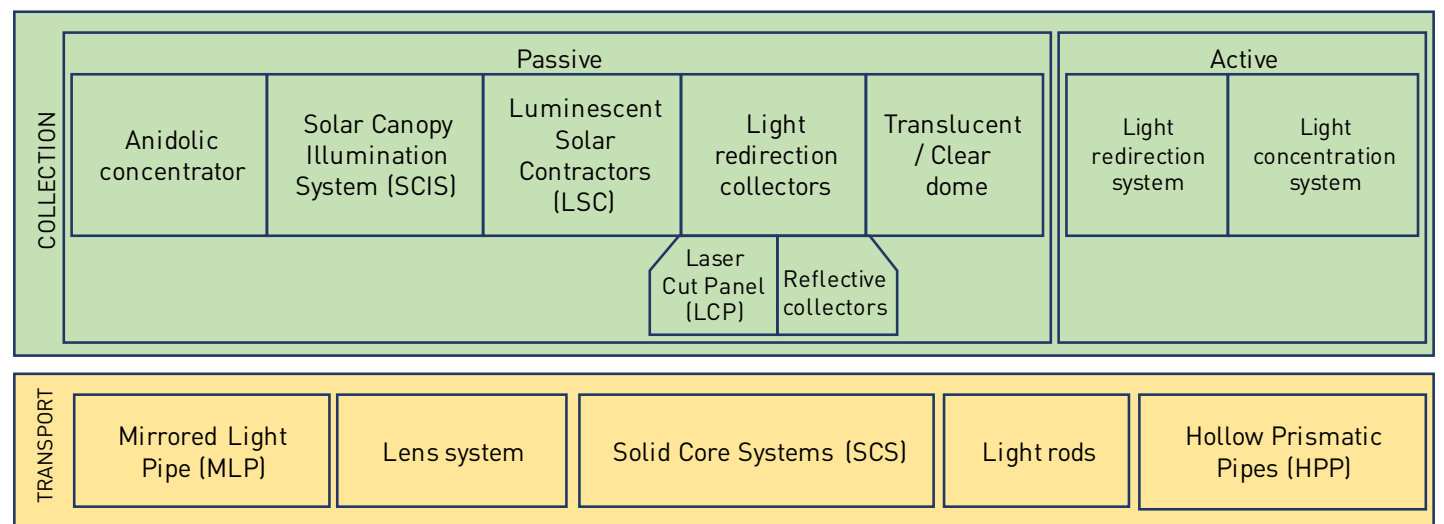

\begin{tabular}{|c|c|c|c|c|c|c|}
\hline 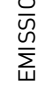 & $\begin{array}{l}\text { Light } \\
\text { extraction }\end{array}$ & $\begin{array}{l}\text { Light } \\
\text { emission }\end{array}$ & $\begin{array}{l}\text { Combined transport } \\
\text { and emission }\end{array}$ & $\begin{array}{l}\text { Discrete } \\
\text { emitter }\end{array}$ & $\begin{array}{l}\text { Other } \\
\text { emitters }\end{array}$ & $\begin{array}{l}\text { Lambertian diffuser and } \\
\text { approached }\end{array}$ \\
\hline
\end{tabular}

Fig. 1. Summary of collection, transport and emission processes with identified technologies in the literature

- Solar Canopy Illumination System (SCIS);

- Luminescent Solar Contractors (LSC);

- Light redirection collectors;

- Translucent dome.

\section{1) Anidolic concentrators}

Anidolic concentrators are devices placed on the facade, coupled with horizontal pipes (Figure 2). These systems are a compound of parabolic concentrators used to collect light at the entrance of the device and concentrate it towards a smaller opening. These are special light shelves that use curved specular reflectors, designed to take advantage of the diffuse light of the sky. Potential glare from direct solar radiation must be controlled by a mobile sunscreen at the entrance to the anidolic system.

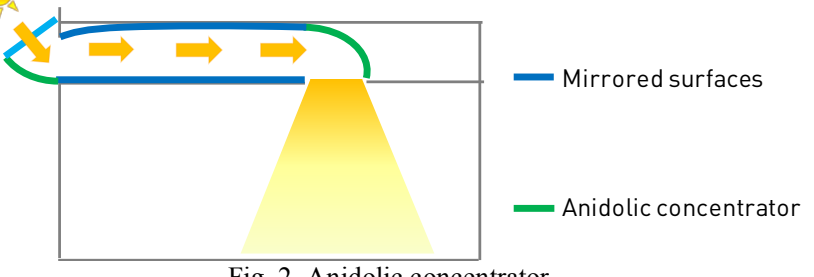

Fig. 2. Anidolic concentrator

The advantage of this system is related to its very high performance in overcast or clear skies. However, the size of the collector on the facade makes it an architecturally difficult system to integrate.

The anidolic concentrator technology continues to be studied (Figure 3). In 2014, Taengchum proposed to combine the collection technology of the anidolic concentrator with a circular light pipe [9].

Further studies have been conducted on this device [10] [11] [12] [13] [14] [15] [16] [17].

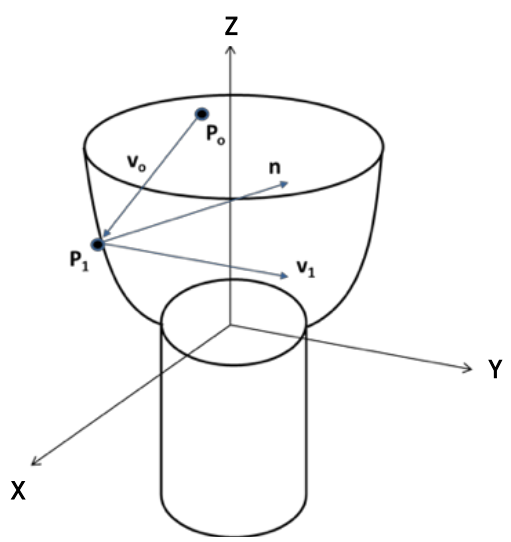

Fig. 3. Anidolic concentrator coupled with circular light pipe [9]

2) Solar Canopy Illumination System (SCIS)

In 2008, Rosemann et al. proposed and evaluated the performance of a collection device using reflective swivel blades (Figure 4). The device is called Solar Canopy Illumination System (SCIS) and is mounted directly above the front window. The device also incorporates artificial lighting to provide additional light if necessary [18].

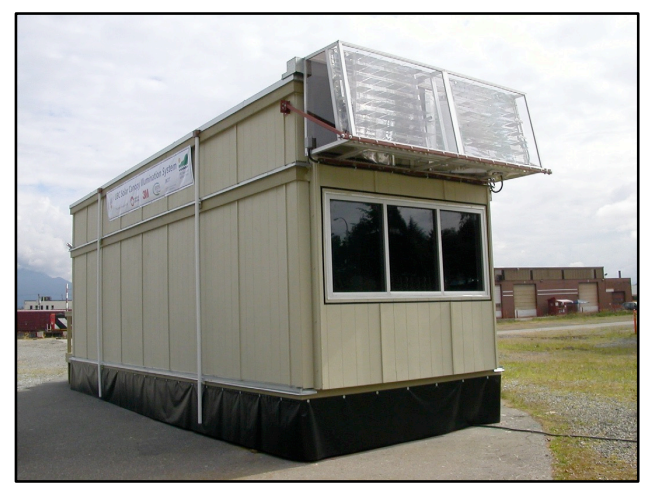

Fig. 4. Solar Canopy Illumination System - SCIS [18]

Another study was conducted in 2010 to show the effectiveness of the SCIS system in enhancing its use in construction projects that must meet the Anglo-Saxon LEED certification [19].

\section{3) Luminescent Solar Contractors (LSC)}

LSC is another process designed to concentrate light. This system consists of a thin plate made of a highly transparent material (polymethyl methacrylate - PMMA), which is doped with fluorescent dyes (Figure 5). The dye molecules absorb 
some of the solar radiation incident on the plate and re-emit fluorescent radiation that is transported to the edges of the plate by internal reflection.

Using colour filters, white light can be obtained. The advantage of this process is that the absorption of incident light does not depend on the solar altitude. The system can operate at any angle of incidence. In addition, it offers the advantage of concentrating the diffuse part of the light as well as the direct part. However, the main limitation of the LSC is its low luminous efficacy with less than $10 \%$ of the incident light at the output. In addition, the premature degradation of dyes (particularly blue and violet) by UV rays and the inefficiency of dyes to transport light make it a somewhat limited system in use. Studies have examined the performance of the LSC applied to the building [20] [21] [22]. PV applications also use the LSC device [23].

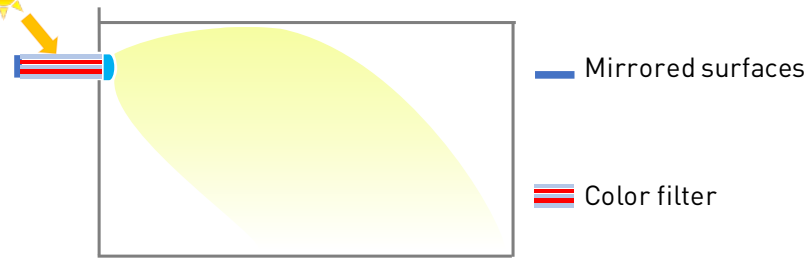

Fig. 5. Luminescent Solar Contractors - LSC

\section{4) Light redirection collectors}

\section{a) Reflective collector}

Reflective collectors are designed using highly reflective flat or curved materials to redirect maximum illumination towards the opening of the light pipe. This process does not concentrate the light, it optimizes the light supply. This type of collector offers an ideal solution to compensate for the presence of a mask near the opening of the tube (Figure 6). In 2007, Duc Hien and Chirarattananon proposed a new light pipe system based on the use of mirrors to concentrate and direct the collected light (Figure 7). This innovative process is part of the family of reflective collectors. The authors use an experimental system and model the performance of their system by taking into account the heat inputs generated [24].

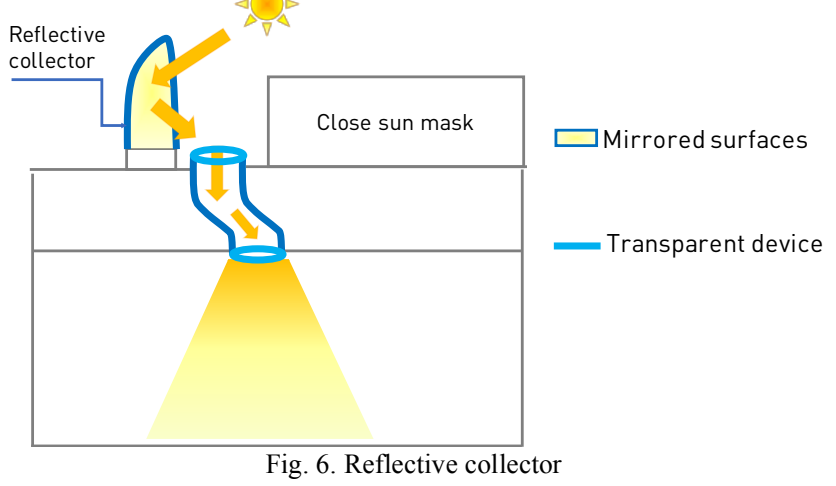

In 2009, Duc Hien [25] presented more detailed results on the experimental study of their light guide device. In addition, it uses a study based on ray throw to evaluate the light transmission of the process. They concluded theirs experimental and numerical studies by indicating that the system provides sufficient illumination for areas far from the lateral openings for clear and overcast sky conditions.

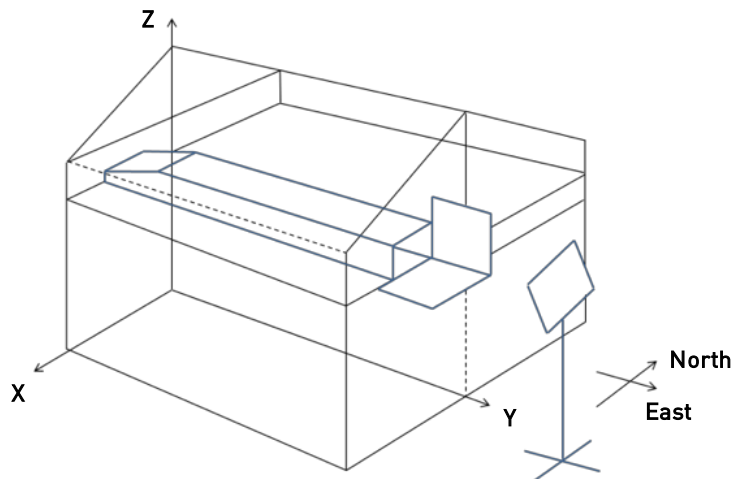

Fig. 7. Duc Hien and Chirarattananon device's [24]

b) Laser Cut Panel - LCP

The Laser Cut Panel is a system that redirects light through laser cuts in acrylic material (Figure 8). These panels provide good visibility to the outside. Placed vertically, they reduce the light input for rays with high incidence angles $\left(>30^{\circ}\right.$, during the day) and collect low incidence rays (morning and evening). Placed horizontally, they act as sun protection. They can be used as a fixed or mobile system. To avoid some glare risks, they must be located above visual level. The Laser Cut Panel is an expensive product, limiting its use.

In 1995, Edmonds and Moore [26] proposed a first study on LCP. They established theoretical equations of light transmission for a single pipe and for a pipe equipped with an LCP. These equations were compared and validated by an experiment on a commercial light pipe. They concluded that the light pipe equipped with deflector blades is more efficient for use in multi-storey buildings.

In 1996, Edmonds et al. provided a second study on LCP as a zenithal opening, highlighting the ability of the device to reject light rays for high solar altitudes, and, on the contrary, to allow rays of low solar altitudes to penetrate [27].

In 1997, Edmonds et al. described the development of a device for the extraction and distribution of light from a remote light source based on LCP technology. The authors developed a theory for the extractor and the designed diffuser, combined with a rectangular and horizontal light pipe [28].

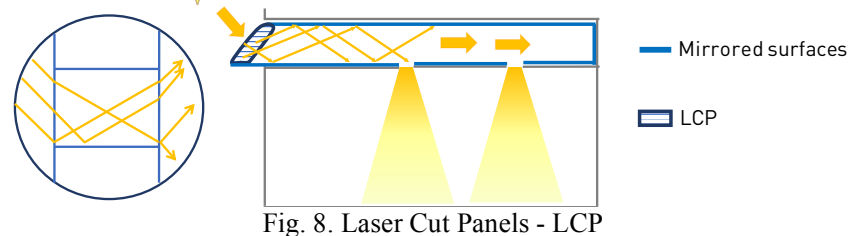

In 2009, Garcia Hansen evaluated and compared the performance of two types of collectors (passive and active, see Figure 9) coupled with a mirrored light pipe [29]. The active system corresponds to an inclined and rotating LCP ( $360^{\circ}$ rotation in 24 hours). The passive system consists of using the pyramid-shaped LCP. The results show that the LCP passive system improves the performance of the mirrored light pipe by 2.5 times, while the active process increases its performance by 5 times when compared to an open device (without collector) for low solar altitudes. A few years earlier [30] demonstrated that the LCP device provided a required level of illumination in sunny weather conditions with an overall efficiency of nearly $32 \%$ (ratio between incoming and outgoing light flux). In overcast conditions, these performances were lower (18\%). 
Since then, the technology has continued to be studied and developed [31].

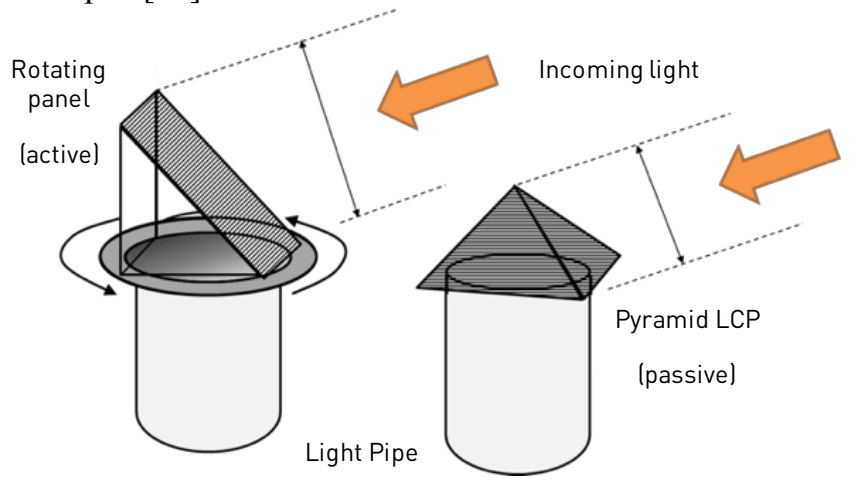

Fig. 9. LCP collector studied by Hansen [29]

In 2015, the manufacturer SOLATUBE introduced a new range of redirecting passive collectors called SkyVault ${ }$, similar to LCP (Figure 10). It is a cylindrical polycarbonate collector containing prisms to redirect light from $10^{\circ}$ to $25^{\circ}$ and using deflectors for low incidence rays. The manufacturer announces that the device provides three times more efficiency than a conventional dome collector.

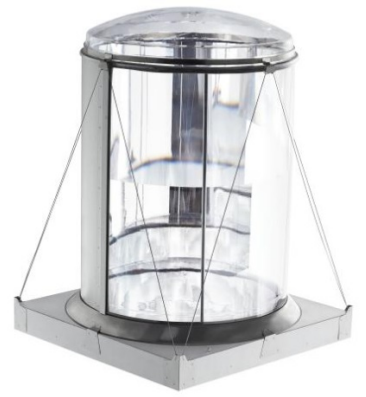

Fig. 10. Skyvault collector by SOLATUBE® (www.solatube.com)

\section{5) Translucent / transparent dome}

This collection technology is the most widely used, marketed and studied. The collector has a dome made of a highly transparent material (polymethyl methacrylate PMMA). Some manufacturers equip it with striations that act as a prism to optimize light collection, or with Fresnel lenses (Figure 11).
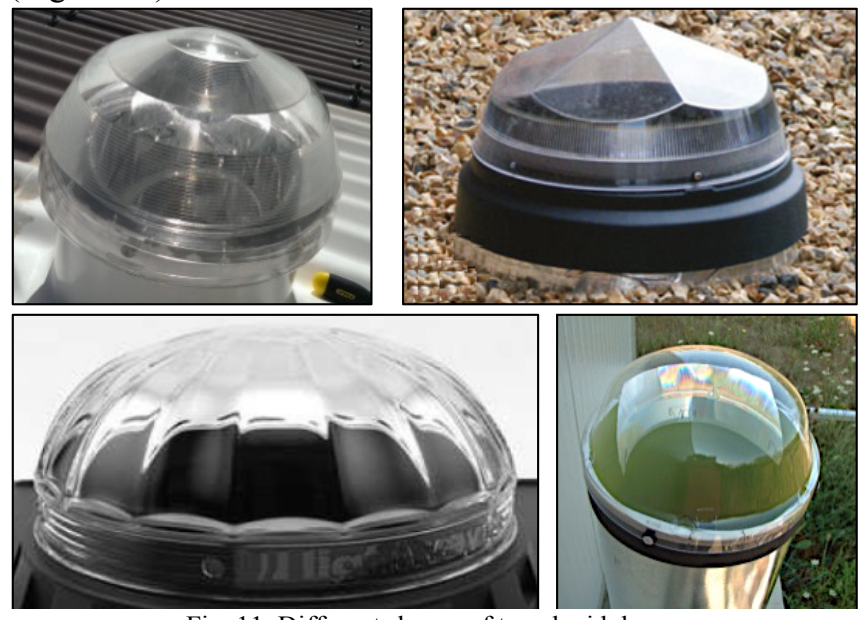

Fig. 11. Different shapes of translucid dome

This system can also be equipped with deflectors of different shapes made of highly reflective material offering increased performance for low incidence light rays. They may also contain various light-concentration technologies such as LCP [26].

Numerous studies have demonstrated the performance of this device [3], [32], [33], [34], [35].

\section{B. Active collectors}

These collectors use an active system to follow the solar path by orienting the collector in the direction of the sun. The main advantage of this system is the collector could be collected the maximum amount of light available at any time of the day, without having a large pipe section. However, this type of product remains expensive due to the fact that it requires a particular design coupled with sensors controlled by a program. In addition, the mobile part of the system requires increased maintenance. In 2009, Lee provided an overview of solar tracking devices [36].

- Two types of active collectors have been identified:

- Light redirection systems;

- Light concentrations systems.

\section{1) Light redirection systems}

Often called Heliostat, they are mechanized flat mirrors usually placed on the roof of a building. They track the position of the sun and redirect the light to the light guide device. It can also be designed using lenses, curved mirrors or Fresnel lenses.

In 2005, Rosemann and Kaase presented the results of the Arthelio project (Figure 12). This involves examining the possibility of guiding daylight to the buildings center. To do this, two technologies were used. The prototype is a pipe whose diffusion is linear. It is coupled to a heliostat system using redirecting lenses and mirrors, and is located in Berlin, Germany [37].

Other studies on heliostat have been conducted [38], including Luo in 2019, which showed the economic feasibility of the system [39].

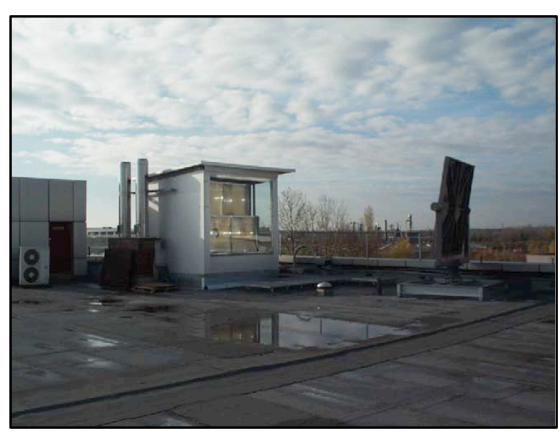

Fig. 12. Reflective collector (Arthelio) [37]

2) Light concentrations systems

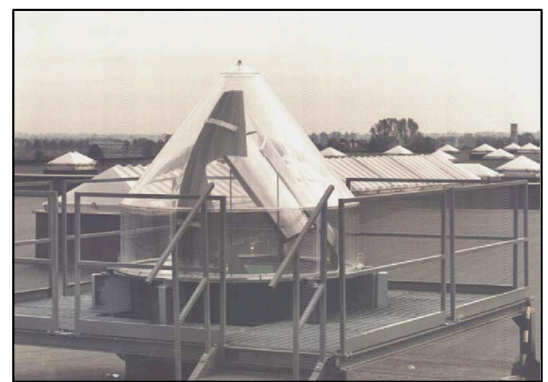

Fig. 13. Active light concentrator Arthelio [37]

This process concentrates the light rays using curved reflectors or Fresnel lenses. Rosemann and Kaase [37] are studying in their project a second configuration installed in Carpien, Italy. Fresnel lenses offer a simple way to concentrate the light, then direct it to the transport device (Figure 13). 
The collection systems using Fresnel lenses commonly found in the literature are the Parans system or the Himawari system (Figure 14).

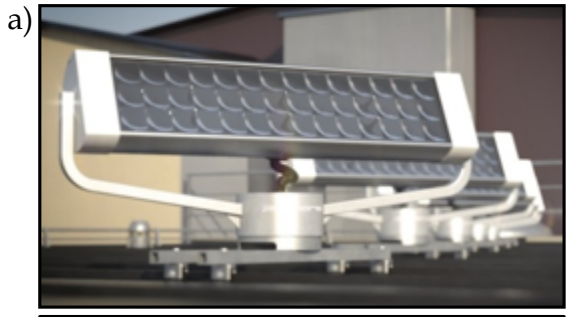

b)

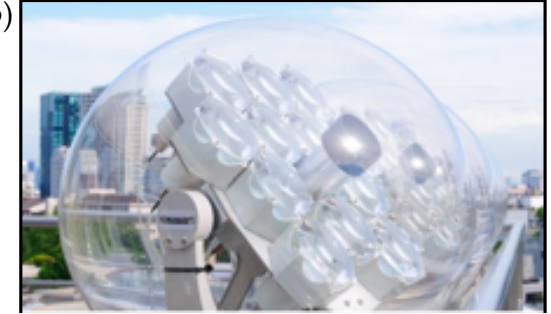

Fig. 14. a) Parans device (www.parans.com) ; b) Himawari device

Other forms of concentrators are available in the literature, such as the Sundolier [40], using the principle of a parabola that concentrates the light rays directly towards the tube. We also find the Hybrid Solar Lighting (HSL) device presented in Mayhoub's publication (Figure 15). This device, like the Parans system, only distributes the direct part of the lighting [41], which makes it effective in clear sky conditions and mediocre in overcast conditions.
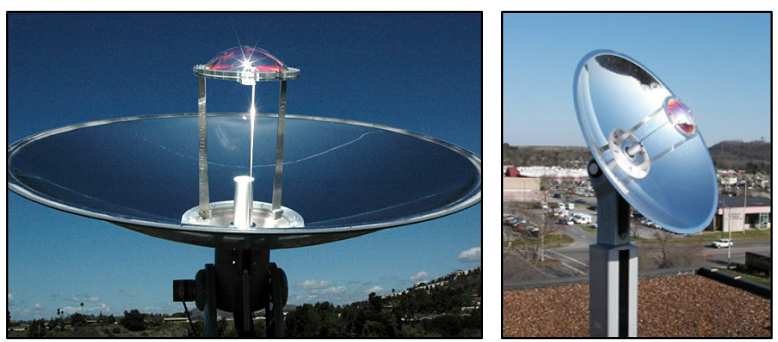

Fig. 15. Hybrid Solar Lighting - HSL [41]

\section{TUBES}

Light beam transport systems are classified according to the material used, whose optical properties differ from one material to another. Indeed, light can be transported by:

- Multiple specular reflection (Mirrored Light Pipe MLP);

- Total internal reflection (optical fiber or prismatic pipe);

- Refraction by converging surface (lenses);

- Diffusion (acrylic or fluid pipe).

Associated with these phenomena, we note the different systems of transport of light [42] :

- Prismatic light pipe;

- $\quad$ Mirrored pipe;

- Pipe with lenses;

- Optical fiber;

- Acrylic pipe;

- Fluid pipe.

The optical properties of the systems also change according to the angle of incidence of incoming rays. This is qualified by a parameter called acceptance angle which plays an important role in the performance of the light pipe (Figure 16).

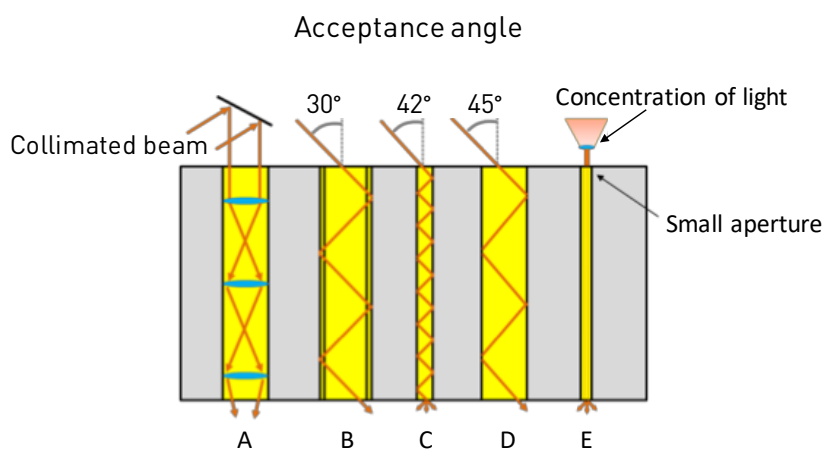

Fig. 16. Different methods of transmitting light rays depending on the angle of incidence of the rays:

a) Lenses ; b) Hollow Prismatic Pipe ; c) Light rod ; d) Mirrored Light Pipe and e) Optical fibers [46]

\section{A. Hollow prismatic pipes - HPP}

This process was developed by Lorne Whitehead [43].

The prismatic light pipe is a hollow light tube in which light is directed through total internal reflections from a prismatic dielectric surface (Figure 17) [44]. The light beam must be located at most $26^{\circ}$ from the central axis of the tube in order to be propagated by total internal reflections.

The guide can be of any section. Square, rectangular and circular shapes are the most common. The prismatic light pipe can be used to transport light to the center of a building, and to efficiently distribute and distribute light along the surface of the path (Figure 18). Light can be transported on average almost thirty meters away [45], [37].

Studies have shown that the energy savings generated by the use of this process vary according to the type of sky. Indeed, the system only really works when the sky is clear, generating an energy saving of around 64\%, compared to $39 \%$ per overcast sky.

HPP can be coupled with artificial lighting. This combination makes it possible to achieve uniform interior lighting, lighting of large spaces or streets, lighting of tunnels and bridges, aesthetic lighting (decoration, architecture, show, etc.), road lighting guides, or a coherent coupling of daylight and artificial light within a building.
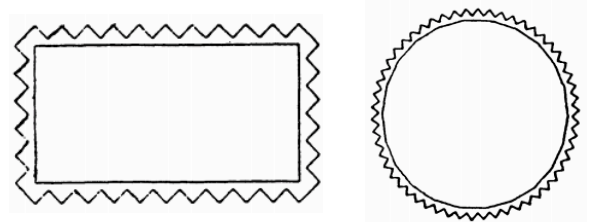

Fig. 17. Section of prismatic pipe [44]

In contrast to the mirrored pipe offering illumination values ranging from 100 lux to 1200 lux (depending on the time of day and the type of sky), HPP coupled with artificial lighting makes it possible to achieve an average illumination throughout the tube of around 200 lux on average [46].

In 2010, Fernandez-Balbuena studied the performance of this type of device installed in an office [47].

We also identify devices close to HPP, such as the Heliobus system [48] that can play both a transport and collection role (Figure 18). 

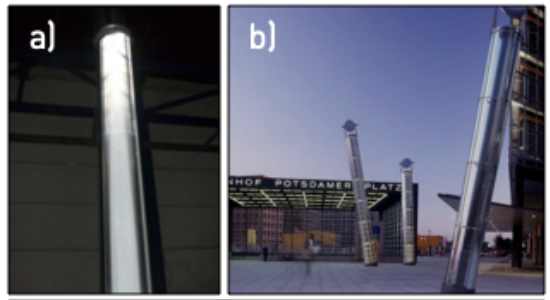

c)

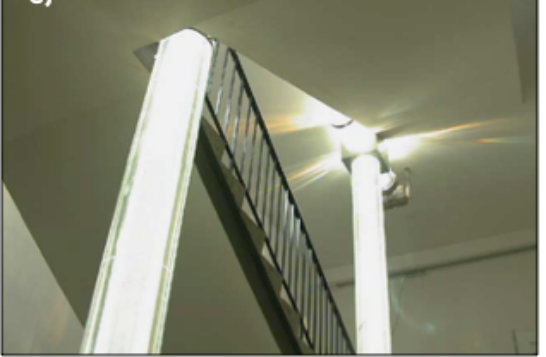

Fig. 18. Prismatic pipe used to transport and distribute light a) [45] ; b) Arthelio Project [37] ; c) Heliobus [48]

\section{B. Pipe with lens}

The lens light tube is a lens arrangement, in which each individual lens transmits an image from the previous lens to the next (Figure 19). Transport is done through the sequence of the convergence/divergence process. A physical tube is not necessary between the lenses. The lens spacing depends on the degree of collimation of the light source. Large lenses can be expensive, unless a Fresnel or annular lens is used. Light can be transported on average up to about thirty meters. Light losses are due to lenses with a transmittance of $92 \%$ [46]. It is important to note that this system remains very fragile because if the lenses move, the whole system is affected.

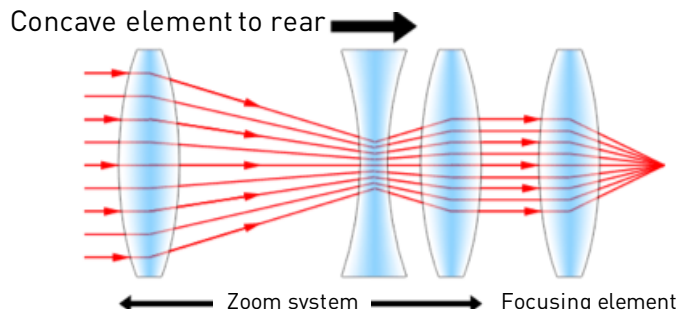

Zoom lens at wide-angle setting

Fig. 19. Overlay transport of converging and diverging lenses [46]

\section{Solid Core Systems - SCS}

This technical process uses the optical fiber as a light conductor and transmits light by total internal reflections through a solid, highly efficient thin fiber. The advantage of optical fiber is that it transmits almost all of the incident luminous flux at the output [49]. The parameter influencing the effectiveness of the SCS is its length (unlike MLP, for diameter). Optical fiber for light transport is called Solid Core Fiber Optics because of its much larger diameter than optical fiber for information.

Light transmission within the optical fiber depends on the optical properties of the material [50], i.e. the loss of the line (in the range of $0.1 \mathrm{~dB} / \mathrm{m}$ to $0.6 \mathrm{~dB} / \mathrm{m}$ for lengths in the range of $18 \mathrm{~m}$ to $30 \mathrm{~m}$ ), the acceptance angle and the aperture, which indicates the propagation of the beam of light accepted by the fiber (sinus of the acceptance angle).

The advantage of optical fiber lies mainly in its ability to transport light to areas far away from all light sources by removing infrared and ultraviolet rays. Moreover, due to its flexibility and relatively small size, its implementation possibilities within a building are not limited.

On the roof, panels composed of all the fiber outlets make it possible to obtain large collection areas in relation to the number of fibers connected. The most popular commercially available system using optical fibers is the Himawari, manufactured by La Foret Engineering in Japan. The Himawari system consists of a honeycomb collector made of hexagonal Fresnel lenses that filters and concentrates light to transport it using optical fiber (Figure 14). Quartz-based optical fiber cables transmit light for special applications where light must be filtered to obtain an optimal rendering. However, these systems are very expensive. Light can be transported on average up to 90 meters.

Jin Oh [51] made a comparison between two devices: the light pipe and the optical fiber coupled to a concentrator on the basis of simulation under the Photopia and Radiance software for a conference room. His study highlighted the benefits of the systems studied for daylight capture, mainly for optical fiber for solar altitudes below $50^{\circ}$.

\section{Light rods}

Light rods are a transport technology based on the principle of total internal reflection, just like optical fiber (Figure 20). The difference with the latter device is the rigidity of the rod.
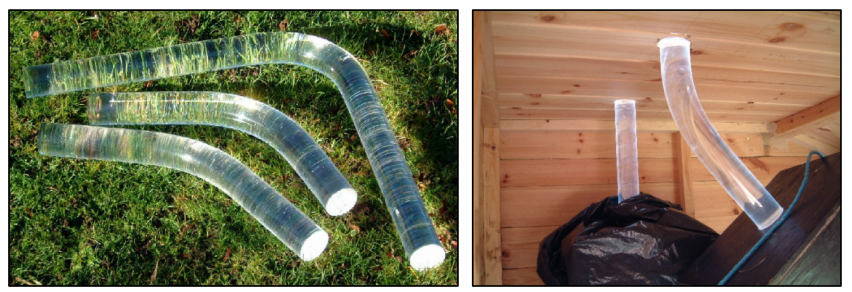

Fig. 20. Light Rods [52]

It has been found that the light rod achieves a higher transmission than the mirrored light pipe for a much smaller diameter, favouring the use of this technology in spatially limited areas [52], [53].

The maximum luminous flux measured at the output is approximately $360 \mathrm{~lm}$ per rod. The curvature up to $90^{\circ}$ of the rods only causes a loss of $20 \%$ of the amount of light transported. Small diameter light rods allow effective light transmission at lengths greater than $4 \mathrm{~m} \mathrm{[53].}$

\section{E. Mirrored Light Pipe-MLP}

Mirrored light pipe use the phenomenon of multiple specular reflection to transport incoming light through the reflectivity of their inner surface (Figure 21). The overall transmission is a function of surface reflectivity, length ratio (i.e. aspect ratio), collector type used, angle of entry of incident light and sky type [3], [32], [34]. Using a highly reflective polyester film ( $>99 \%$ ), light can be transmitted up to 30 meters with only low losses. These systems can transmit the diffuse part of the light, but with a lower efficiency.

The evolution of the device is linked to the evolution of the reflective material (reflection coefficient). Here are some materials that have been or are being used:

- Polished aluminum: $85 \%$

- Silver coated plastics / Aluminium: 95\%.

- Miro-silver (aluminium improved with PVD process): 98\%

- Polished aluminium: $85 \%$. 
- Silvered aluminium: $95 \%$.

- Miro-silver (aluminium improved with PVD process): $98 \%$.

- Spectralight infinity (SOLATUBE): $99.7 \%$.

This type of tube can be coupled to both active collectors (Sun tracking systems) and passive collectors (Laser Cut Panels, Translucent Dome).

One of the advantages of this product is that it transmits less heat than a zenithal opening, such as a skydome [3], [35].
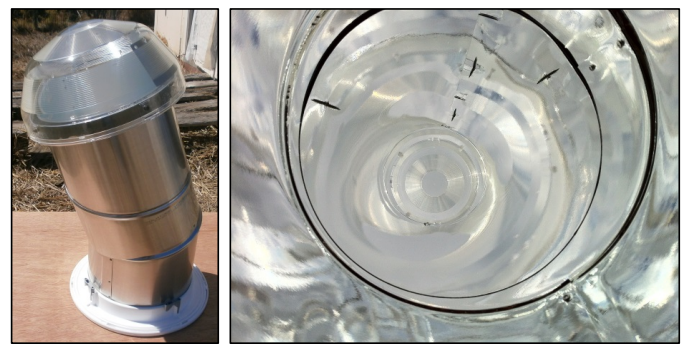

Fig. 21. Mirrored Light Pipe with translucid dome [33]

These performances decrease with increasing length ratio, but also with the number of curves [6], [54].

Vertical pipes using MLP are generally circular. For horizontal pipes, rectangular or triangular sections are mainly used [55].

MLP may also have other configurations. In the literature, studies have focused on the use of the mirrored light pipe for daylight and ventilation. Indeed, by means of a temperature difference between inside and outside or by the pressure difference due to the air flow around the tube outside, and by using an adequate MLP, a thermal gradient ventilation can be obtained [56], [57].

Mirrored pipe can also be horizontal (Figure 22). In this configuration, studies showed that, the mirrored tube is effective for short lengths. In the case of large buildings, it is difficult to collect light on roofs. For this reason, the light is supplied from the facade, the associated duct being horizontal. Collectors from the previous section can be used. We can cite the example of the pipe described by Canziani [58] as well as that of Chirarattananon [59].

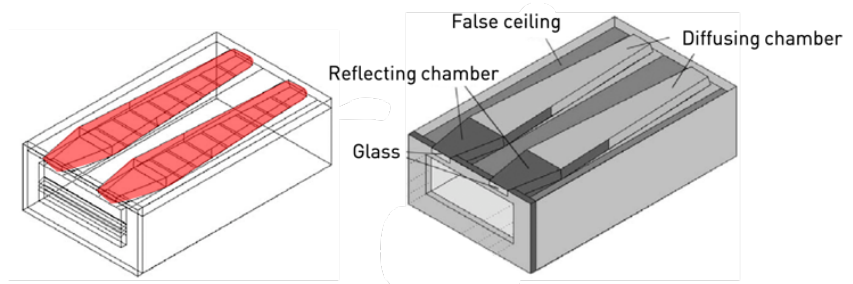

Fig. 22. Horizontal Mirrored Light Pipe [58]

The anidolic concentrator coupled to the horizontal mirrored light pipe is commonly studied [60]. The combination of the two devices offers an interesting compromise in terms of the amount of light delivered and diffused uniformly in the receiving room (Figure 23).

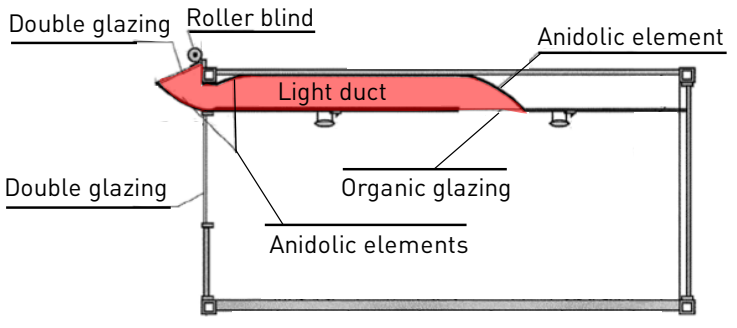

Fig. 23. Anidolic Concentrator / Horizontal Mirrored Light Pipe Association [60]
Researchers have focused on the use of horizontal configuration for buildings located in dense urban areas [61], [62]. Kwok has coupled Laser Cut Panels collection technology with horizontal mirrored light pipe. MLP can be tilted using elbows to restore the inclination (Figure 24). The pipe can be inclined from $5^{\circ}$ to $90^{\circ}$. However, in the building, this angle varies from $20^{\circ}$ to $60^{\circ}$ [5].

The inclined collector collects daylight from the "seen" part of the sky as well as light reflected from the ground and opposite facades [5].

The mirrored light pipe is a Tubular Reflective Light Guide Device. This device is the most widely marketed and studied internationally.

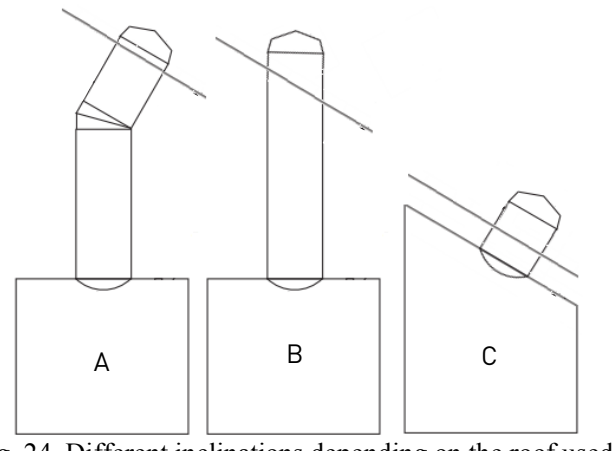

Fig. 24. Different inclinations depending on the roof used a) Pipe with elbow, collector in the roof plane; b) Vertical pipe, horizontal collector; c) Pipe perpendicular to the inclined plane of the roof and ceiling, collector in the plane of the roof

\section{DIFFUSER}

In this section, we distinguish two processes related to the diffusion of light in the room: light extraction and light emission. Light extraction is carried out at the end of the pipe, throughout the tube or at certain parts of it. The type and complexity of the diffuser will depend mainly on the type of light pipe.

\section{A. Light extraction}

Edmonds [28] described the principle of light extraction related to MLP as follows: a certain proportion of light can be extracted at various intervals along the vertical light pipe illuminating various floors or at different levels of a horizontal light pipe to obtain uniform illumination. In the example in Figure 25, each extractor is reflective enough to deflect a quarter of the light equally.

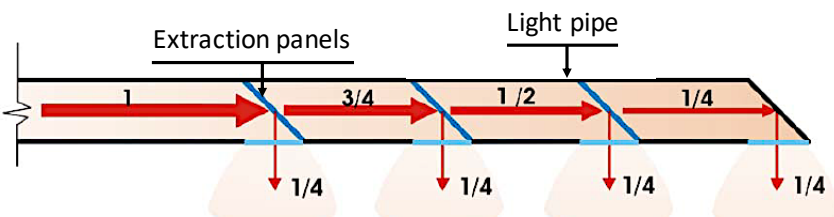

Fig. 25. Light extraction [28] [46]

\section{B. Light emission}

Ayers and Carter [63] designated the transmitter as a device that distributes and diffuses light from the transport system. Its characteristics will depend on the system to which it is attached. Ayers and Carter describe two types of emitters: those that combine transport and emission in which the light, collected by the collector, is extracted along its length, or the separate emitters that function as a conventional luminaire by redistributing the light delivered by the pipe. 


\section{1) Diffuser combining transport and emission}

Typical examples of this type of diffuser-pipe combining transport and emission are prismatic hollow pipe (HPP) (2\% loss every $300 \mathrm{~mm}$, diffuse light, risk of glare), double light pipe (conduit with highly reflective film) or optical fiber (use in decoration or signage). This type of system is both a light conductor and a light diffuser.

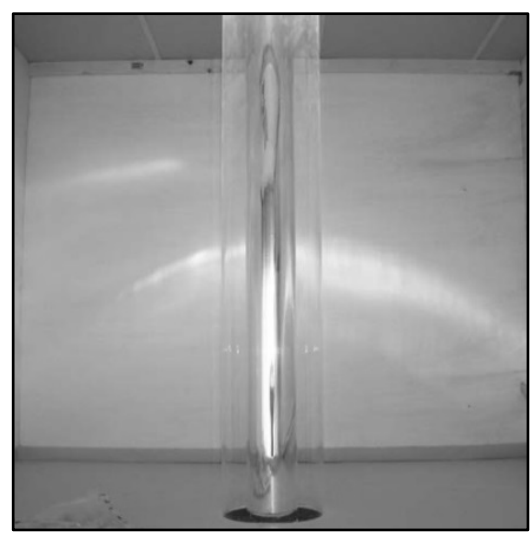

Fig. 26. Double Light Pipe - DLP [8]

In 2010, Baroncini et al [8] are digitally and experimentally analyzing a new light pipe system based on the combination of two tubes: the first tube has its inner and outer reflecting walls and is positioned inside the second translucent tube (with diffusive walls). This device, called Double Light Pipe(DLP), combines the technique of a traditional mirrored light pipe and the technicality of linear diffusion described by Rosemann [37]. Thus, it allows light to be directed to a given point, while illuminating the tube's passage areas (Figure 26).

\section{2) Separate diffuser}

Separate diffusers are transmitters that are almost independent of the transport device. Indeed, they allow to redistribute, redirect, divert or concentrate the light rays coming from the transport device. Typical examples of this type of separate diffuser are tunnel lights (conductalite), optical fiber coupled with Fresnel lenses (Parans system), inclined mirror diffusers, concave lenses and Fresnel lenses (solar light flux emitters) (Figure 27) [63].

Mayhoub studied the "Parans" device by coupling it with an artificial lighting device giving rise to the HLS, Hybrid Lighting System [41].

a) Light Guide

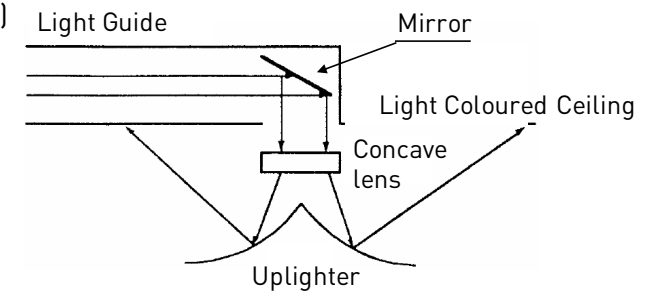

b)

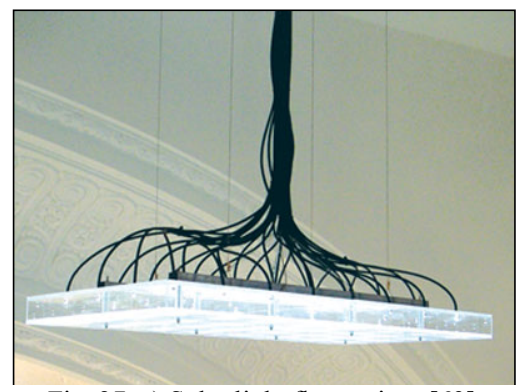

Fig. 27. a) Solar light flux emitter [63] ;

b) Parans device (www.parans.com)

\section{3) Others diffusers}

Other emitters are emerging, using, for example, known technologies in the collection of light. A typical example is the use of the Laser Cut Panel (LCP) as an emitter (Figure 28). Using this known technology, it deflects light from the pipe to the ceiling [46].

\begin{tabular}{|l|l|}
\hline Extracted light & Leflected light \\
Laser cut light \\
spreading panel \\
Office space
\end{tabular}

Fig. 28. Use of LCP technology as a diffuser [46]

\section{4) Lambertian diffusers and assimilated}

These diffusers are the most common means of transmission. They can be circular (the most common) or rectangular. Several diffusion surfaces are available according to needs (Figure 29). They can be transparent or translucent. In the latter case, the surface can be prismatic, equipped with Fresnel lenses, or striations. These devices act as the interface between the light pipe and the area to be illuminated. In the literature, authors often tend to consider that the device diffuses and distributes light in a Lambertian way (luminance is independent of emission direction), which is not really the case [32], [64].

For the rest of the state of the art, we will focus on the following couple: translucent dome / mirrored light pipe/ prismatic diffuser. This association is the most widely used and studied internationally and has been the subject of an experimental study in tropical climates with strong solar deposits.
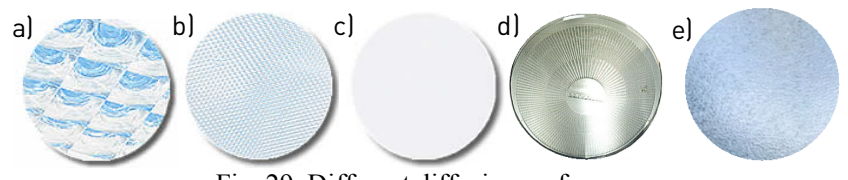

Fig. 29. Different diffusion surfaces

a) Fresnel lens translucent diffuser ; b) Prismatic translucent diffuser ; c)

Transparent diffuser ; d) Stripe diffuser ; e) Granulated glass diffuser

\section{The Mirrored Tubular Daylight Guide Systems INDUSTRY}

The concept of the Mirrored Light Pipe is not new. The principle of the device seems to have been developed by the ancient Egyptians, recognized as being the first to bring light by reflection (Mirrored TDGS).

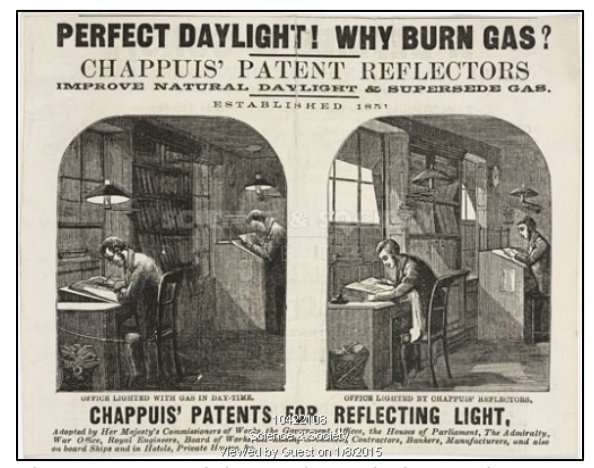

Fig. 30. Press article on Chappuis' innovation [65] 
The first commercial reflector systems were patented and marketed in the 1850 s by Paul Emile Chappuis in London, using various configurations and shapes of inclined mirrors (Figure 30). Chappuis reflectors were in continuous production until the factory was destroyed in 1943 [65].

He filed several patents for his various devices:

- Diamond-shaped reflector (also called myriastratic or diamond-shaped);

- Fluted and silver plated glass reflector (also called silverfluted glass);

- $\quad$ Silver and crystal reflector (also called argento-crystal);

- "Luminarium" reflector.

It was not until 1986, in Australia, that the first light pipe appeared in the most commercial form in the 21 st century: the highly reflective light pipe. It is better known by its AngloSaxon name: MLP, for Mirrored Light Pipe.

The SOLATUBE company, at the initiative of the application for this patent, has been developing the product for almost 30 years. Figure 31 shows the evolution of the collector, marketed as the "dome".
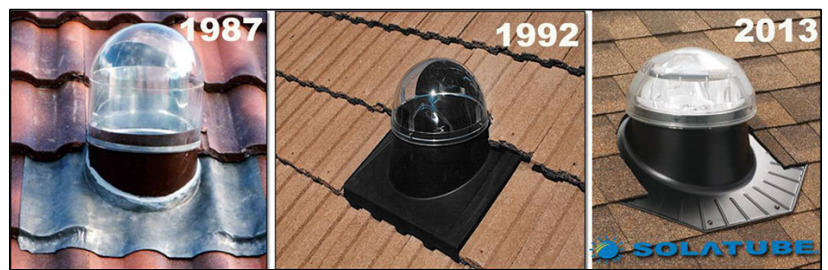

Fig. 31. Evolution of the translucid dome over the last 30 years (www.solatube.com)

The shape of this element has changed significantly. In the 2000s, the dome became flatter. This form has proved to be more efficient in collecting as much daylight as possible, ensuring that solar radiation is collected at $180^{\circ}$. Once entirely translucent, the Australian company's collector is now equipped with prisms to deflect and redirect rays with low incidence angles within the tube.

This device is improved by many manufacturers who equip it with directional collector (Heliostat, allowing to follow the solar path), reflector or Fresnel lens (allowing to clip the light rays to avoid overcurrent).

Developed in 2003 at the Queensland University of Technology in Brisbane, the LCP (Lazer Cut Panel) is a collector configuration consisting of a laser-cut acrylic panel designed to redirect sunlight to the tube oriented horizontally or vertically. The inventors of this device are Veronica Garcia Hansen, Ken Yeang, and Ian Edmonds, well-known authors in scientific research on technological innovations in lighting.

Today, light pipes are manufactured and marketed by many brands. Each manufacturer offers its own light collection system, a tube with a wall reflection coefficient approaching 1 (currently 99.7\%), and a diffuser increasingly adapted to visual comfort. Performance is also improved: in its publication [2], Kim states that this device theoretically guides the collected light rays up to 4 to 8 storeys lower with a distribution at each storey extending up to 15 meters horizontally across the building structure through reflective or optical devices. The improvement of lighting conditions can also depend on many other parameters [32].

Currently, different light pipe systems are available on the market and each system has its own characteristics and efficiency. Kim proposes a non-exhaustive list of the brands and products offered [2]. A summary of Kim's work is provided in Table 1 (in appendix) for the top five manufacturers.

\section{CONCLUSION}

This paper presented the Tubular Daylight Guide Systems in their entirety. This process performs three functions at the same time: collecting daylight, transporting it through a tube, and diffusing it into the building. Commonly referred to as a "light pipe", the terminology in the literature is vast to quote the same device.

We have shown that the TDGS is a global system broken down into a collector, a transport system and a diffuser. Multiple variations for these three parts are counted, and continue to evolve even thirty years after the first light pipe. The combinations of technologies offer a diversity in the performance of the TDGS and a wide range of innovation.

The elements presented make it possible to target the state of the art in the study of light pipe devices. The technology continues to be developed to increase the supply of daylight and reduce the energy consumption associated with the use of artificial lighting during the day.

Several studies have found that light collection is the function of the light pipe to be optimized [32], [34], [66], [67]. The prospects for improvement should focus on increasing the capture of global external illuminance while ensuring low cost and maintenance.

\section{APPENDIX}

TABLE 1: SUMMARY THE TOP FIVE MANUFACTURERS OF MiRRORED TUBULAR DAYLIGHT GUIDE SYSTEMS [2]

\begin{tabular}{|l|l|l|}
\hline $\begin{array}{l}\text { Brand } \\
\text { name }\end{array}$ & $\begin{array}{l}\text { Product and technical } \\
\text { details }\end{array}$ & Picture \\
\hline & $\begin{array}{l}\text { Suncatcher } \\
\text { Air intakes in all } \\
\text { directions; Thermal } \\
\text { draught; Solar tracker }\end{array}$ & \\
\hline & $\begin{array}{l}\text { MonoventSuncatcher } \\
\text { Cost-effective; } \\
\text { Lightweight; Compact } \\
\text { solar tracker }\end{array}$ & \\
\cline { 2 - 3 } & $\begin{array}{l}\text { Sola-vent } \\
\text { Integrated artificial } \\
\text { lighting via PV power } \\
\text { supply; air extractor }\end{array}$ \\
\hline \multirow{2}{*}{$\begin{array}{l}\text { Tube length up to 9m ; } \\
\text { air extractor possible }\end{array}$}
\end{tabular}




\begin{tabular}{|c|c|c|}
\hline & $\begin{array}{l}\text { Solatube Daylighting } \\
\text { System SolaMaster }{ }^{\circledR} \\
\text { System does not } \\
\text { require a finished } \\
\text { ceiling; Use of a } \\
\text { rectangular diffuser; } \\
\text { discreet roof opening }\end{array}$ & 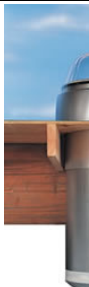 \\
\hline \multirow{2}{*}{$\begin{array}{l}\stackrel{凶}{S} \\
\text { 夏 }\end{array}$} & $\begin{array}{l}\text { Daylighting } \\
\text { Domeshape } \\
\text { Rigid tube (increased } \\
\text { reflection coefficient) } \\
\text { or flexible tube (easily } \\
\text { installed) }\end{array}$ & \\
\hline & $\begin{array}{l}\text { Daylighting Rectangle } \\
\text { shape } \\
\text { Flat collector made of } \\
\text { tempered glass; Roof } \\
\text { slope between } 15^{\circ} \text { and } \\
60^{\circ}\end{array}$ & \\
\hline 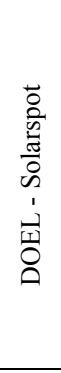 & $\begin{array}{l}\text { Mirrored light pipe, } \\
\text { straight or elbowed } \\
\text { Additional solar } \\
\text { tracker ; Multiple } \\
\text { diffusers (Prismatic } \\
\text { diffuser, Fresnel } \\
\text { diffuser, Vision } \\
\text { diffuser, Lamp } \\
\text { diffuser); } \\
\text { polycarbonate dome; }\end{array}$ & \\
\hline 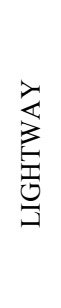 & $\begin{array}{l}\text { Lightway Crystal / } \\
\text { Silver } \\
\text { Treated glass dome; } \\
\text { Multilayer alloy tube; } \\
\text { Anti-reflective treated } \\
\text { glass diffuser; anti- } \\
\text { condensation solution } \\
\text { ("Blue performance") }\end{array}$ & \\
\hline
\end{tabular}

\section{REFERENCES}

[1] P. J. Littlefair, « Review Paper: Innovative daylighting: Review of systems and evaluation methods ", Light. Res. Technol., vol. 22, no 1 , p. 1-17, mars 1990 .

[2] J. T. Kim et G. Kim, "Overview and new developments in optical daylighting systems for building a healthy indoor environment », Build. Environ., vol. 45, no 2, p. 256-269, févr. 2010.

[3] X. Zhang, T. Muneer, et J. Kubie, «A design guide for performance assessment of solar light-pipes », Light. Res. Technol., vol. 34, no 2, p. 149-168, juin 2002.

[4] D. Jenkins et T. Muneer, «Light-pipe prediction methods », Appl. Energy, vol. 79, no 1, p. 77-86, sept. 2004.

[5] S. Darula, M. Kocifaj, R. Kittler, et F. Kundracik, «Illumination of interior spaces by bended hollow light guides: Application of the theoretical light propagation method », Sol. Energy, vol. 84, no 12, p. 2112-2119, déc. 2010 .

[6] D. J. Carter, «The measured and predicted performance of passive solar light pipe systems », Light. Res. Technol., vol. 34, no 1, p. 39-51, 2002.

[7] Y. Wu, R. Jin, D. Li, W. Zhang, et C. Ma, « Experimental investigation of top lighting and side lighting solar light pipes under sunny conditions in winter in Beijing », présenté à International Conference on Optical Instruments and Technology: Advanced Sensor Technologies and Applications, 2008, p. 71571O-71571O-6.

[8] C. Baroncini, O. Boccia, F. Chella, et P. Zazzini, «Experimental analysis on a 1:2 scale model of the double light pipe, an innovative technological device for daylight transmission », Sol. Energy, vol. 84 no 2, p. 296-307, févr. 2010.
[9] T. Taengchum, S. Chirarattananon, R. H. B. Exell, et P. Chaiwiwatworakul, « Tracing of daylight through circular light pipes with anidolic concentrators », Sol. Energy, vol. 110, p. 818-829, déc. 2014.

[10] M. G. Nair, « Performance studies of anidolic concentrator with light pipes for day lighting in buildings », International Journal of Scientific \& Engineering Research, vol. 5, no 7, 2014.

[11] G. Courret, « Systèmes anidoliques d'éclairage naturel », EPFL, 1999.

[12] S. C. Molteni, G. Courret, B. Paule, L. Michel, et J. L. Scartezzini, «Design of anidolic zenithal lightguides for daylighting of underground spaces », Sol. Energy, vol. 69, p. 117-129, 2001.

[13] M. Roshan et A. S. Barau, « Assessing Anidolic Daylighting System for efficient daylight in open plan office in the tropics », J. Build. Eng., vol. 8, p. 58-69, déc. 2016.

[14] F. Binarti et P. Satwiko, « Long-term Monitoring and Simulations of the Daylighting and Thermal Performance of an Anidolic Daylighting System on a Tropical Urban House », Energy Procedia, vol. 78, p 1787-1792, nov. 2015.

[15] J.-L. Scartezzini et G. Courret, « Anidolic daylighting systems », Sol. Energy, vol. 73, no 2, p. 123-135, août 2002.

[16] F. Linhart, S. K. Wittkopf, et J.-L. Scartezzini, «Performance of Anidolic Daylighting Systems in tropical climates - Parametric studies for identification of main influencing factors », Sol. Energy, vol. 84, no 7, p. 1085-1094, juill. 2010.

[17] G. Courret, J.-L. Scartezzini, D. Francioli, et J.-J. Meyer, « Design and assessment of an anidolic light-duct », Energy Build., vol. 28, no 1, p. 79-99, août 1998 .

[18] A. Rosemann, M. Mossman, et L. Whitehead, « Development of a costeffective solar illumination system to bring natural light into the building core », Sol. Energy, vol. 82, no 4, p. 302-310, avr. 2008.

[19] T. Russell, P. Duvall, et S. Davies, « An Investigation Into Renewable Energy: The Solar Canopy Illumination System », nov. 2010.

[20] A. A. Earp, G. B. Smith, J. Franklin, et P. Swift, « Optimisation of a three-colour luminescent solar concentrator daylighting system », Sol. Energy Mater. Sol. Cells, vol. 84, no 1-4, p. 411-426, oct. 2004.

[21] B. C. Rowan, L. R. Wilson, et B. S. Richards, "Advanced Material Concepts for Luminescent Solar Concentrators », IEEE J. Sel. Top. Quantum Electron., vol. 14, no 5, p. 1312-1322, sept. 2008.

[22] N. Aste, L. C. Tagliabue, P. Palladino, et D. Testa, « Integration of a luminescent solar concentrator: Effects on daylight, correlated color temperature, illuminance level and color rendering index », Sol. Energy, vol. 114, p. 174-182, avr. 2015.

[23] A. Reinders, M. G. Debije, et A. Rosemann, « Measured Efficiency of a Luminescent Solar Concentrator PV Module Called Leaf Roof», IEEE J. Photovolt., vol. 7, no 6, p. 1663-1666, nov. 2017.

[24] V. Duc Hien et S. Chirarattananon, « Daylighting through Light Pipe for Deep Interior Space of Buildings with Consideration of Heat Gain », p. 461-475, 2007.

[25] V. D. Hien et S. Chirarattananon, « An experimental study of a facade mounted light pipe », Light. Res. Technol., vol. 41, no 2, p. 123-142, juin 2009.

[26] I. R. Edmonds, G. I. Moore, G. B. Smith, et P. D. Swift, « Daylighting enhancement with light pipes coupled to laser-cut light-deflecting panels », Light. Res. Technol., vol. 27, no 1, p. 27-35, mars 1995.

[27] I. R. Edmonds, P. A. Jardine, et G. Rutledge, «Daylighting with angular-selective skylights: Predicted performance», Light. Res. Technol., vol. 28, no 3, p. 122-130, sept. 1996.

[28] I. R. Edmonds, J. Reppel, et P. Jardine, « Extractors and emitters for light distribution from hollow light guides », Light. Res. Technol., vol. 29, no 1, p. 23-32, mars 1997.

[29] Garcia Hansen, V., Edmonds, I., et Bell, J. M., «Improving Daylighting Performance of Mirrored Light Pipes », présenté à PLEA2009 - 26th Conference on Passive and Low Energy Architecture, Quebec City, Canada, 2009.

[30] V. Garcia Hansen et I. Edmonds, « Natural illumination of deep-plan office buildings: light pipe strategies », in Faculty of Built Environment and Engineering; Faculty of Science and Technology; School of Design, Göteborg, Sweden, 2003.

[31] M. G. Nair, A. R. Ganesan, et K. Ramamurthy, «Daylight enhancement using laser cut panels integrated with a profiled Fresnel collector », Light. Res. Technol., p. 1477153514556524 , oct. 2014.

[32] B. Malet-Damour, S. Guichard, D. Bigot, et H. Boyer, « Study of tubular daylight guide systems in buildings: Experimentation, modelling and validation », Energy Build., vol. 129, p. 308-321, oct. 2016.

[33] B. Malet-Damour, H. Boyer, S. Guichard, et F. Miranville, «Performance Testing of Light Pipes in real weather conditions for a confrontation with Hemera », présenté à ICRET 2014, Hong Kong Chine, 2014. 
[34] D. Jenkins et T. Muneer, «Modelling light-pipe performancesnatural daylighting solution », Build. Environ., vol. 38, no 7, p. 965-972, juill. 2003.

[35] L. Shao, A. A. Elmualim, et I. Yohannes, "Mirror lightpipes Daylighting performance in real buildings », Light. Res. Technol., vol. 30, no 1, p. 37-44, mars 1998.

[36] C.-Y. Lee, P.-C. Chou, C.-M. Chiang, et C.-F. Lin, « Sun tracking systems: a review », Sensors, vol. 9, no 5, p. 3875-3890, 2009.

[37] A. Rosemann et H. Kaase, "Lightpipe applications for daylighting systems », Sol. Energy, vol. 78, no 6, p. 772-780, juin 2005

[38] J. Song, G. Luo, L. Li, K. Tong, Y. Yang, et J. Zhao, « Application of heliostat in interior sunlight illumination for large buildings », Renew. Energy, vol. 121, p. 19-27, juin 2018.

[39] G. Luo, L. Li, J. Wang, W. Wang, J. Song, et Y. Yang, « A heliosta integrated with a sun-position sensor for daylighting », Energy Procedia, vol. 158, p. 394-399, févr. 2019.

[40] [40] W. R. McCluney, L. Kinney, et J. Hutson, « Tracking Solar Lighting System for Core Building Spaces and Underground Ones », in Light, Energy and the Environment (2017), paper RW4A.3, 2017, p. RW4A.3.

[41] M. Mayhoub et D. Carter, « Hybrid lighting systems: Performance and design », Light. Res. Technol., vol. 44, no 3, p. 261-276, sept. 2012.

[42] J. Schuman, F. Rubinstein, K. Papamichael, L. Beltran, E. Lee, et S. Selkowitz, "Technology Reviews: Daylighting Optical Systems », 1992.

[43] [L. A. Whitehead, R. A. Nodwell, et F. L. Curzon, « New efficient light guide for interior illumination », Appl. Opt., vol. 21, no 15, p 2755-2757, août 1982 .

[44] O. Dobrre et G. Achard, "Optical simulation of lighting by hollow light pipes ", présenté à Ninth International IBPSA Conference, Montréal, Canada, 2005, p. 263-270.

[45] D. Vazquez-Molini, A. Alvarez, et B. Garcia-Fernandez, « Natural Lighting Systems Based on Dielectric Prismatic Film », in Dielectric Material, M. A. Silaghi, Éd. InTech, 2012.

[46] V. G. Hansen, «Innovative Daylighting Systems For Deep-Plan Commercial Buildings », Thèse Sci., School of Design Queensland University of Technology, 2006.

[47] A. A. Fernandez-Balbuena, Daniel Vazquez-Moliní, Berta GarcíaFernandez, Lucas García-Rodríguez, et Teresa Galán-Cañestro, «Daylight illumination system by vertical Transparent Prismatic Lightguide for an office building ", présenté à Colour and Light in Architecture_First International Conference 2010_Proceedings, 2010 , p. 360-365.

[48] M. S. Mayhoub, « Fifty years of building core sunlighting systems Eight lessons learned », Sol. Energy, vol. 184, p. 440-453, mai 2019.

[49] Carter, « Developments in tubular daylight guidance systems », Build Res. Inf., vol. 32, no 3, p. 220-234, mai 2004.

[50] L. Audin, «Plasma lighting, fiber optics, and daylight collectors: Toward the next revolution in high-efficiency illumination », Strateg. Plan. Energy Environ., vol. 14, no 4, juin 1995.
[51] S. J. Oh, W. Chun, S. B. Riffat, Y. I. Jeon, S. Dutton, et H. J. Han, "Computational analysis on the enhancement of daylight penetration into dimly lit spaces: Light tube vs. fiber optic dish concentrator », Build. Environ., vol. 59, p. 261-274, janv. 2013.

[52] J. Callow, «Daylighting Using Tubular Light Guide Systems », University of Nottingham, 2003

[53] L. Shao et J. M. Callow, « Daylighting performance of optical rods », Sol. Energy, vol. 75, no 6, p. 439-445, déc. 2003

[54] G. Oakley, S. . Riffat, et L. Shao, «Daylight performance of lightpipes », Sol. Energy, vol. 69, no 2, p. 89-98, 2000.

[55] I. Edmonds, "Transmission of mirror light pipes with triangular, rectangular, rhombic and hexagonal cross section », Sol. Energy, vol. 84, no 6, p. 928-938, juin 2010.

[56] A. C. Oliveira, A. R. Silva, C. F. Afonso, et S. Varga, « Experimental and numerical analysis of natural ventilation with combined light/vent pipes ", Appl. Therm. Eng., vol. 21, no 18, p. 1925-1936, déc. 2001.

[57] S. Varga et A. C. Oliveira, "Ventilation terminals for use with light pipes in buildings: a CFD study », Appl. Therm. Eng., vol. 20, no 18, p. 1743-1752, déc. 2000

[58] R. Canziani, F. Peron, et G. Rossi, « Daylight and energy performances of a new type of light pipe », Energy Build., vol. 36, no 11, p. 1163-1176, nov. 2004

[59] S. Chirarattananon, S. Chedsiri, et L. Renshen, « Daylighting through light pipes in the tropics », Sol. Energy, vol. 69, no 4, p. 331-341, 2000.

[60] S. Wittkopf et al., « Ray tracing study for non-imaging daylight collectors ", Sol. Energy, vol. 84, no 6, p. 986-996, juin 2010.

[61] C. Kwok, "A study of horizontal light pipe system for interior daylighting in a dense urban environment », Thesis, The Hong Kong Polytechnic University, 2011.

[62] C. M. Kwok et T. M. Chung, "Computer simulation study of a horizontal light pipe integrated with laser cut panels in a dense urban environment », Light. Res. Technol., vol. 40, no 4, p. 287-305, déc. 2008 .

[63] M. J. Ayers et D. J. Carter, « Remote source electric lighting systems: A review », Light. Res. Technol., vol. 27, no 1, p. 1-15, mars 1995.

[64] J. Mohelnikova, «Tubular light guide evaluation », Build. Environ. vol. 44, no 10, p. 2193-2200, oct. 2009.

[65] I. Visa et A. Duta, Nearly Zero Energy Communities: Proceedings of the Conference for Sustainable Energy (CSE) 2017. Springer, 2017

[66] M. S. Mayhoub, «Innovative daylighting systems' challenges: A critical study », Energy Build., vol. 80, p. 394-405, 2014.

[67] Malet-Damour B, Bigot D, Guichard S, Boyer H. Photometrical analysis of mirrored light pipe: From state-of-the-art on experimental results (1990-2019) to the proposition of new experimental observations in high solar potential climates. Sol Energy 2019;193:637-53. doi:10.1016/j.solener.2019.09.082. 